\title{
Comparative study and optimization of the mechanical behavior of sandwich beams loaded in three point bending
}

\author{
Bourouis F*, Mili F \\ University of Mentouri Brothers Constantine 1, Faculty of Engineering Science, Laboratory of Mechanics \\ Chaab Ersas 25000 Constantine, Algeria. \\ * Corresponding Author: famo006@yahoo.fr, mifauniversite@gmail.com
}

\author{
Received: 08-02-2018 $\quad$ Revised: 24-03-2018 $\quad$ Accepted: 08-04-2018
}

\begin{abstract}
The sandwich material presents a certain interest in term of rigidity and specific resistance for the aeronautic structure design. The study of this material meets always the choice problem of their constituents (coating and core) in order to find the optimal mechanical characteristic. The aim of this work is to do a comparative study of the mechanical behavior of the sandwich beams loaded in three point bending. The structures considered consist of two skins of composite material with unidirectional fibers of six plies Glass/epoxy, Carbon/epoxy or Kevlar/epoxy of stacking sequence $\left[0^{\circ} / 90^{\circ}\right]_{3 \mathrm{~s}}$ and $\left[45^{\circ} /\right.$ $\left.45^{\circ}\right]_{3 s}$ and the core is in Alporas , Corecel, PVC, or Polyurethane foams. The different results obtained from the Matlab code showed that the correct choice of the material of the coatings and of the core that improves the mechanical behavior of the sandwich beam. In order to increase the performance of sandwich beams, in three points bending, an optimization program based on the principles of genetic algorithms has been developed to maximize the tensile strength of face yielding and face wrinkling failure modes. The equations used to evaluate the individuals in population results from the classical laminate theory with transverse shear stresses and discrete variables. Operators of genetic algorithms (selection, crossover and mutation) are applied to the children of a hundred generations. To achieve optimal solutions, the result appeared effective despite all the non-deterministic nature of genetic algorithms. But, to achieve maximum effectiveness, it's important to choose smartly the parameters of genetic algorithms depending on the nature of the problem studied and the mechanical characteristics of the function to be optimized.
\end{abstract}

Key words: Sandwich beam; three point bending; face wrinkling; face yielding; genetic algorithm.

\section{Introduction}

The importance of studying the bending behavior of beams is related to the use of beams as basic elements of structures, as well as to the mechanical characterization of laminates and sandwichs using test specimens in the form of beams (Berthelot, 1996). A number of researchers have studied the mechanical behavior and optimization of sandwich structures in flexure. The static and fatigue behavior of acuum-assisted resin transfer molded sandwich panels has been experimentally investigated under flexural loading by Jin and Thomas (2003). Two core materials, D-100 balsa wood and H 250 PVC foam, were used to study the effect of core material on static failure in 3-point and 4-point bending. A good similarity was seen between the static and fatigue failure modes for both short span and long span specimens. The comparison of sandwich was described by Craig and Norman (2004). A systematic procedure is presented to compare the relative performance of sandwich beams with various combinations of materials. The geometry of sandwich beams is optimized to minimize the mass for a required load bearing capacity in three-point bending. Compression face wrinkling failures of sandwich columns under compression beams in three and four-point bending and cantilever beams under loading were investigated by Gdoutos et al. (2003) the failure by wrinkling is prevalent in the case of low through-the thickness stiffness and long beam spans. In other cases, other failure modes including shear core failure, compressive facing failure, face sheet debonding or indentation 
failure may occur. Tahani et al. (2005) applied Genetic Algorithm (GA) for simultaneous costs minimization and frequency maximization. The proposed model is applied to a carbon/epoxy, glass/epoxy laminate and results are obtained for various aspect ratios and number of layers. Many researchers have proposed modifications to the classical GA structure to take advantage of composite laminate characteristics and minimize the computational cost (Hamidreza et al., 2012).

The present paper reports on the static behavior and failure modes of sandwich beams under flexure. The structures considered consist of two skins of composite material with unidirectional fibers of six plies Glass/epoxy, Graphite/epoxy or Kevlar/epoxy and the core is in Alporas, Corecel , PVC, or Polyurethane foams. The objective of our work is to do an optimization study of fracture and damage of sandwich beams with composite laminated coating oriented at $\left[+45^{\circ} /-45^{\circ}\right]_{3 s}$ and $\left[0^{\circ} / 90^{\circ}\right]_{3 s}$, the optimal design of sandwich beams loaded in three point bending is treated by using algorithm genetic. Two failure modes were studied face wrinkling and face yielding.

\section{Bending of sandwich beams}

The purpose of this section is to establish the equation for the mechanical behavior and the failure modes of sandwich beams loaded in three point bending.

Consider a sandwich beam loaded in three-point bending as sketched in (Figure 1). Let $L$ be the beam length between the supports, $b$ the width of the beam, $h$, the core thickness, and $h_{1}=h_{2}$ the face thickness. The beam is subject to a distributed load $q$. The load is given by equation (1):

$\mathrm{P}=\mathrm{q} / \mathrm{L}$

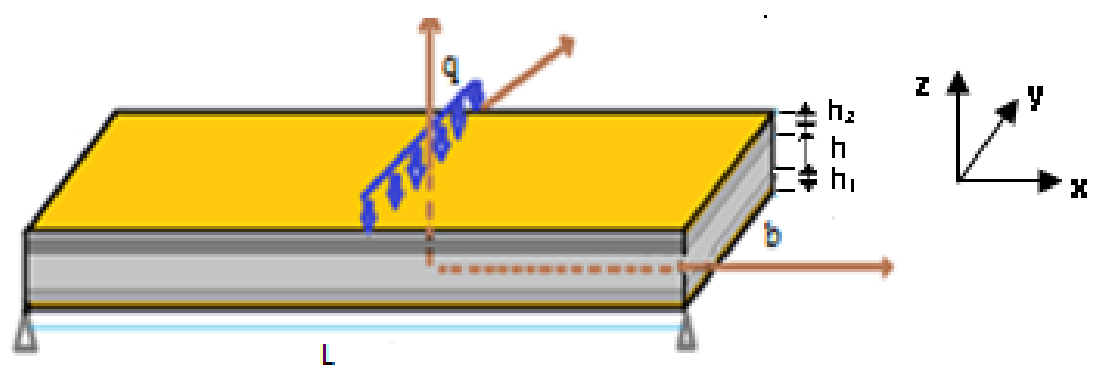

Fig1. Schematization of a sandwich beam loaded in three-point bending

The mechanical characteristics face sheet and core materials are listed in the Tables 1 and 2 (Berthelot, 1996; Ashby, 2000; Zinker, 1995).

Table 1. Properties of face laminate

\begin{tabular}{|c|c|c|c|}
\hline Mechanical characteristics & Glass E/epoxy & Carbon HR/epoxy & Kevlar 49/epoxy \\
\hline \hline $\mathrm{V}_{\mathrm{f}}$ & 0.6 & 0.6 & 0.6 \\
\hline $\mathrm{E}_{\mathrm{L}}(\mathrm{GPa})$ & 46 & 159 & 84 \\
\hline $\mathrm{E}_{\mathrm{T}}(\mathrm{GPa})$ & 10 & 14.3 & 5.6 \\
\hline $\mathrm{G}_{\mathrm{LT}}(\mathrm{GPa})$ & 4.6 & 4.8 & 2.1 \\
\hline$v_{\mathrm{LT}}$ & 0.31 & 0.32 & 0.34 \\
\hline
\end{tabular}

$\mathrm{V}_{\mathrm{f}}$ : Fiber volume fraction, $\mathrm{E}_{\mathrm{L}}$ : Longitudinal young's modulus.

$\mathrm{E}_{\mathrm{T}}$ : Transverse young's modulus, $\mathrm{G}_{\mathrm{LT}}$ : Longitudinal shear modulus. $v_{\mathrm{LT}}:$ Poisson ratio. 
Table 2. Properties of core materials

\begin{tabular}{|c|c|c|}
\hline Foams & Density $\left(\mathrm{Kg} / \mathrm{m}^{3}\right)$ & $\mathrm{G}_{13}(\mathrm{MPa})$ \\
\hline \hline Alporas & 0.09 & 1.01 \\
\hline Polyurethane & 46 & 84 \\
\hline Corecell A300 & 10 & 5.6 \\
\hline PVC H45 & 4.6 & 2.1 \\
\hline PVC H60 & 0.31 & 0.34 \\
\hline PVC H100 & 70 & 35 \\
\hline
\end{tabular}

$\mathrm{G}_{13}(\mathrm{MPa})$ : Longitudinal shear modulus.

\subsection{Mechanical behavior of sandwich beams in three-point bending}

The equations of moments and transverse shear resultants are then given by:

$\left[\begin{array}{l}M_{x} \\ M_{y} \\ M_{x y}\end{array}\right]=\left[\begin{array}{lll}D_{11} & D_{12} & D_{16} \\ D_{12} & D_{22} & D_{26} \\ D_{16} & D_{26} & D_{66}\end{array}\right]\left[\begin{array}{c}K_{x} \\ K_{y} \\ K_{x y}\end{array}\right]$

And

$\left[\begin{array}{c}\gamma_{y z}^{a} \\ \gamma_{x z}^{a}\end{array}\right]=\left[\begin{array}{ll}F_{44}^{*} & F_{45}^{*} \\ F_{45}^{*} & F_{55}^{*}\end{array}\right]\left[\begin{array}{l}Q_{y} \\ Q_{x}\end{array}\right]$

The strains are then given:

$\varepsilon_{\mathrm{xx}}=\mathrm{z} \frac{\mathrm{d} \varphi_{\mathrm{x}}}{\mathrm{dx}}$

$\gamma_{\mathrm{xz}}^{\mathrm{a}}=\varphi_{\mathrm{x}}+\frac{\mathrm{dw}_{0}}{\mathrm{dx}}$

The symmetry of the problem loads permits to consider only half of beam.

In the case of a three point bending the deflection including the transverse shear deformation is given by the equation:

$W_{0}=\frac{P l^{2}}{4 b h^{3} E_{x}} x\left[4\left(\frac{x}{l}\right)^{2}-3-2 S\right] \quad 0 \leq x \leq \frac{l}{2}$

The effective bending modulus of the beam:

$\mathrm{E}_{\mathrm{x}}=\frac{12}{\mathrm{~h}^{3} \mathrm{D}_{11}^{*}}$

The shear coefficient $S$ defined by:

$S=12 \frac{F_{55}^{*}}{D_{11}^{*}}\left(\frac{h}{l}\right)^{2}$

Where $D_{11}^{*}$ given by:

$D_{11}^{*}=\frac{1}{\Delta}\left(D_{22} D_{66}-D_{26}^{2}\right)$

$\Delta=\mathrm{D}_{11} \mathrm{D}_{22} \mathrm{D}_{66}+2 \mathrm{D}_{12} \mathrm{D}_{16} \mathrm{D}_{26}-\mathrm{D}_{11} \mathrm{D}_{26}^{2}-\mathrm{D}_{22} \mathrm{D}_{16}^{2}-\mathrm{D}_{66} \mathrm{D}_{12}^{2}$

The stiffness constants are expressed as:

$D_{i j}=h\left(C_{i j}\right)$ 
We have:

$C_{i j}=\sum_{k=1}^{n}\left(Q_{i j}^{\prime}\right)_{k} e_{k} z_{k}$

And the coefficient $\mathrm{F}_{55}^{*}$ are expressed as:

$F_{55}^{*}=\frac{F_{44}}{\Delta F}$

With:

$\Delta F=F_{44} F_{55}-F_{45}^{2}$

And

$F_{i j}=h C_{i j}^{\prime C}$

$C_{i j}^{\prime C}:$ The transverse stiffness constants.

$C_{44}^{\prime C}=G_{23}^{C}(\cos \theta)^{2}+G_{13}^{C}(\sin \theta)^{2}$

$C_{45}^{C}=\left(G_{13}^{C}-G_{23}^{C}\right) \sin \theta \cos \theta$

$C_{55}^{\prime C}=G_{23}^{C}(\sin \theta)^{2}+G_{13}^{C}(\cos \theta)^{2}$

We consider the sandwich beam with two identical skins with orthotropy directions parallel to the directions $\mathrm{x}$ and $\mathrm{y}$.

The in plane stresses in layer $\mathrm{k}$ of the upper or lower skins are given by relations:

$$
\sigma_{x x}^{k}= \pm \frac{P h}{4 b} D_{11}^{*}\left(Q_{11}^{\prime k}\right) x
$$

\subsection{Failure modes of sandwich beams in flexure}

Sandwich beams may fail by different competing mechanisms, such as face yielding; face wrinkling, core shear and indentation, depending on their geometries and material properties. The face yielding and face wrinkling failure modes together with the corresponding simplistic failure criteria are summarized below:

Face yielding fracture occurs when the normal stress in the face $\sigma_{\mathrm{xx}}^{\mathrm{k}}$ equals or exceeds the (yield) strength of the face material, in tension, such that:

$\sigma_{\mathrm{xx}}^{\mathrm{k}} \geq \sigma_{\mathrm{xu}}^{\mathrm{t}}$

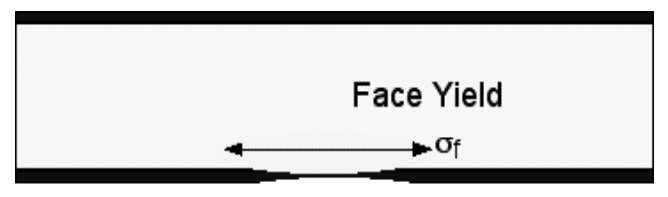

Fig 2. Face yielding failure mode

Face wrinkling due to compression occurs when the normal stress in the face $\sigma_{x x}^{k}$ equals or exceeds the (yield) strength of the face material, in compression, such that:

$\sigma_{x x}^{k} \geq \sigma_{x u}^{\mathrm{c}}$ 


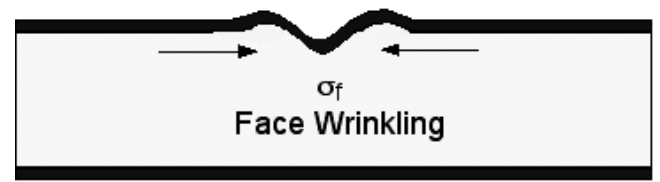

Fig 3. Face wrinkling failure mode

The stresses in the face were calculated using maximum stress criterion and the simple beam theory, including transverse shear effect.

\section{Optimization Process}

The maximum load of the sandwich beam in face wrinkling failure mode $P_{c}$ is equal to:

$P_{c}=\mp \frac{4 b \sigma_{x u}^{c}}{h x D_{11}^{*}\left(Q_{11}^{\prime k}\right)}$

And the maximum load of the sandwich beam in face yielding failure mode $P_{t}$ is equal to:

$P_{c}=\mp \frac{4 b \sigma_{x u}^{t}}{h x D_{11}^{*}\left(Q_{11}^{\prime k}\right)}$

The problem is formulated as: $\quad\left\{\begin{array}{l}\text { Face wrinkling failure mode: Max } P_{c}=\text { Fitness } \\ \text { Face yielding failure mode: Max } P_{t}=\text { Fitness }\end{array}\right.$

The optimization problem was solved using the algorithm genetic. The program can operate on many subpopulations ; number of subpopulation 5 , number of chromosomes 20 , number of genes 6 , probability of mutation 0.2 , probability of crossover 1 . The selection is made by the rank method. The maximum number of generations is fixed to 100 and to seek the performance $F(x)$ of the evolved individuals in this period.

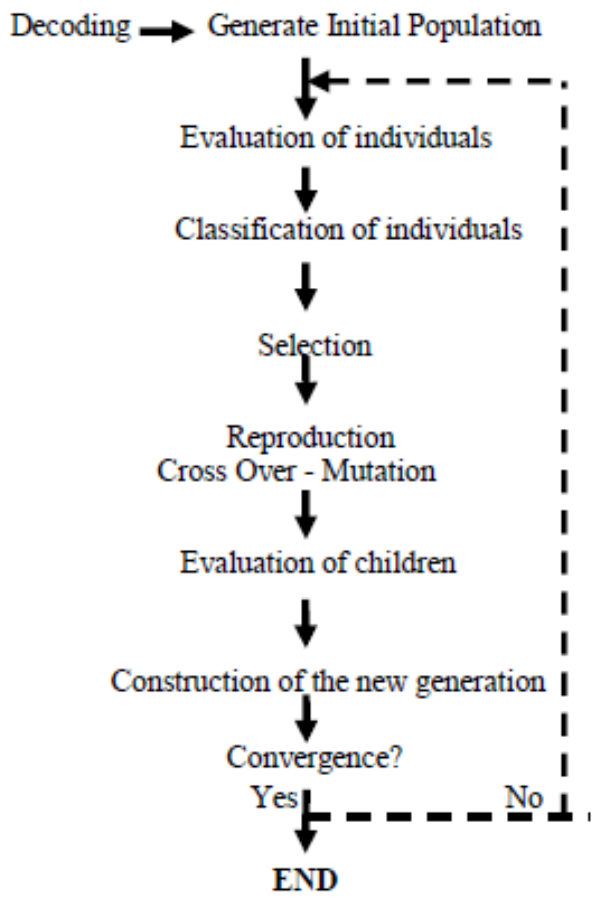

Fig 4. Optimization procedure based on a genetic algorithm 
The aim of this part is to show how to model damage problems from genetic algorithms. This will then lead us to show the advantages of this tool compared to a resolution by an analytical method. We have considered sandwich beams loaded in three-point bending with two identical skins. The possible coatings orientations are around four distinct orientations: $0^{\circ},+45^{\circ},-45^{\circ}$ and $90^{\circ}$. In order to respect the symmetry constraint, only half of the beams that are represented by independent variables.

The representation of the laminates is made on the basis of the genetics concept. An individual is equivalent to a laminate and consequently, the population refers to a group of laminates. An individual can then be represented by one or more chromosomes. Each chromosome contains a chain of genes of the same type representing the coded variables of the problem. Let us take the example of a sandwich structure with laminate composite coatings consisting of six plies.

When the $\omega$ domain comprises four discrete orientations $0^{\circ}, 45^{\circ},-45^{\circ}, 90^{\circ}$, it is necessary to use a coding of four alleles $1,2,3$, 4 . The table 3 gives an example of a six-ply laminate.

Table 3. Encoding the discrete domain $\omega_{\mathrm{i}}$

\begin{tabular}{|c|c|c|c|c|}
\hline Domain & \multicolumn{4}{|c|}{ Variables /alleles } \\
\hline \hline$\omega_{\mathrm{i}}$ (decoded & $0^{\circ}$ & $+45^{\circ}$ & $-45^{\circ}$ & $90^{\circ}$ \\
\hline$\omega_{\mathrm{i}}^{\prime}$ (coded) & 1 & 2 & 3 & 4 \\
\hline
\end{tabular}

Table 4. Representation of a six-ply laminate

\begin{tabular}{|c|c|c|c|c|c|c|}
\hline Representation & \multicolumn{6}{|c|}{ Variables /alleles } \\
\hline \hline Coded & 1 & 2 & 4 & 1 & 3 & 4 \\
\hline Decoded & $0^{\circ}$ & $+45^{\circ}$ & $90^{\circ}$ & $0^{\circ}$ & $-45^{\circ}$ & $90^{\circ}$ \\
\hline
\end{tabular}

We selected an initial population $\left(\mathrm{P}_{0}\right)$ of ten individuals $(\mathrm{N}=10)$, represented by a chromosome $\omega^{\prime}=\{1,2,3,4\}$. In this case, each gene takes aleatory value within the domain and each individual are evaluated in order to determine the values of their performance $\mathrm{F}(\mathrm{x})$. In this contribution, the crossing was chosen in two points.

Table 5. Two-point crossover (X2P)

\begin{tabular}{|c|c|c|c|c|c|c|c|}
\hline Coding-Decoding & \multicolumn{7}{|c|}{ Variables /alleles } \\
\hline \hline \multirow{3}{*}{$\begin{array}{c}\text { Coding a six-ply of } \\
\text { individual }\end{array}$} & $\mathrm{P} 1$ & 1 & 2 & 3 & 4 & 1 & 2 \\
\cline { 2 - 8 } & $\mathrm{P} 2$ & 3 & 2 & 1 & 3 & 2 & 1 \\
\cline { 2 - 8 } & $\mathrm{C} 1$ & 1 & 2 & 1 & 3 & 1 & 2 \\
\cline { 2 - 8 } & $\mathrm{C} 2$ & 3 & 2 & 3 & 4 & 2 & 1 \\
\hline \multirow{3}{*}{$\begin{array}{c}\text { Decoding a six-ply } \\
\text { of individual }\end{array}$} & $\mathrm{P} 1$ & $0^{\circ}$ & $+45^{\circ}$ & $-45^{\circ}$ & $90^{\circ}$ & $0^{\circ}$ & $+45^{\circ}$ \\
\cline { 2 - 8 } & $\mathrm{P} 2$ & $-45^{\circ}$ & $+45^{\circ}$ & $0^{\circ}$ & $-45^{\circ}$ & $+45^{\circ}$ & $0^{\circ}$ \\
\cline { 2 - 8 } & $\mathrm{C} 1$ & $0^{\circ}$ & $+45^{\circ}$ & $0^{\circ}$ & $-45^{\circ}$ & $0^{\circ}$ & $+45^{\circ}$ \\
\cline { 2 - 8 } & $\mathrm{C} 2$ & $-45^{\circ}$ & $+45^{\circ}$ & $-45^{\circ}$ & $90^{\circ}$ & $+45^{\circ}$ & $0^{\circ}$ \\
\hline
\end{tabular}

The simple mutation is applied to children in a probability $\mathrm{P}_{\mathrm{m}}$. During the mutation, a $\mathrm{v}_{\mathrm{k}}$ gene of a child $C$ is chosen at random. This gene is then randomly modified by a value other than $v_{k}$ belonging to the domain $\omega$ '. The third gene $v_{3}$ is mutated and its value changes from 3 to 1 .

Table 6. Example of a simple mutation

\begin{tabular}{|c|c|c|c|c|c|c|}
\hline \multicolumn{7}{|c|}{ Variables /alleles } \\
\hline \hline $\mathrm{P}_{1}$ & 1 & 2 & 3 & 4 & 1 & 2 \\
\hline $\mathrm{P}_{2}$ & 1 & 2 & 1 & 4 & 1 & 2 \\
\hline $\mathrm{C}_{1}$ & $0^{\circ}$ & $+45^{\circ}$ & $-45^{\circ}$ & $90^{\circ}$ & $0^{\circ}$ & $+45^{\circ}$ \\
\hline $\mathrm{C}_{2}$ & $0^{\circ}$ & $+45^{\circ}$ & $0^{\circ}$ & $90^{\circ}$ & $0^{\circ}$ & $+45^{\circ}$ \\
\hline
\end{tabular}


The parameters of the genetic algorithm used during the generation of the results are given in Table 7.

Table 7. Genetic algorithm parameters.

\begin{tabular}{|c|c|c|c|c|}
\hline $\mathrm{N}$ & $\mathrm{Nk}$ & Crossover & Mutation & Stop criterion \\
\hline \hline & & $\mathrm{X} 2 \mathrm{P}$ & Simple & tn \\
\hline 10 & 5 & 1,00 & 0.2 & 100 \\
\hline
\end{tabular}

\section{Results and discussion}

\subsection{Comparative study of the mechanical behavior of sandwich beams loaded in three-point bending}

In order to study the influence of the nature of the constituent materials of the sandwich structure; we considered thin beams $400 \mathrm{~mm}$ long, $50 \mathrm{~mm}$ wide and $\mathrm{h}=13 \mathrm{~mm}$ high. Consisting of two identical skins of thickness $\mathrm{h}_{1}=\mathrm{h}_{2}=1.5 \mathrm{~mm}$ (Figure 1 ). The structures considered consist of two skins of composite material with unidirectional fibers of six plies. The beams are subjected to a distributed load $\mathrm{P}=-70 \mathrm{~N} / \mathrm{m}$.

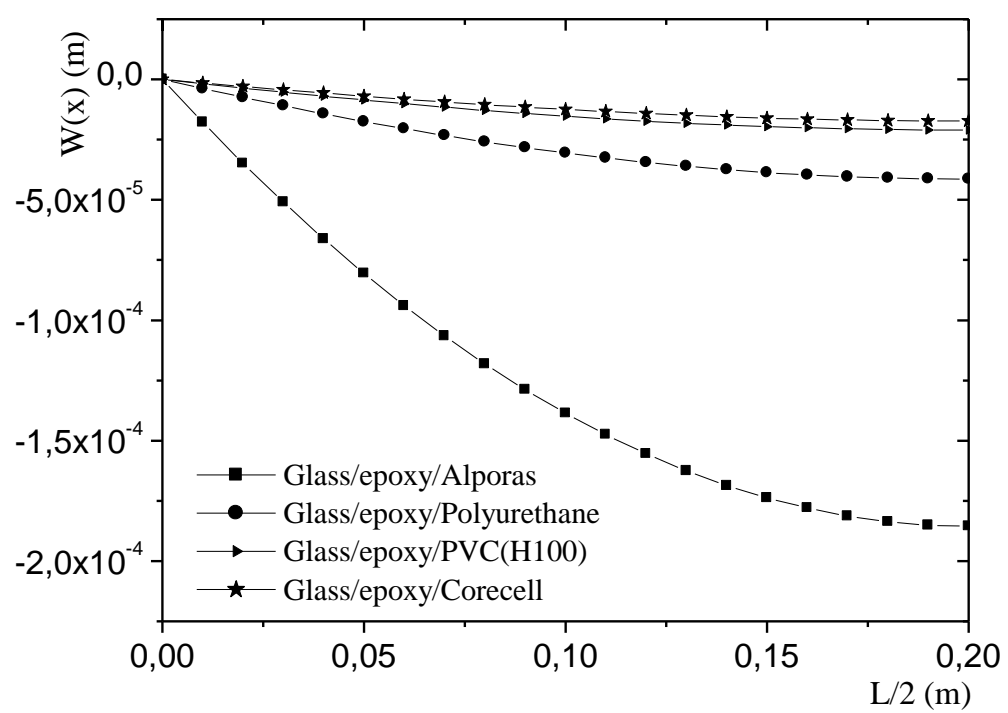

Fig5. Variation of the deflection of a sandwich beam with different core materials and glass/epoxy coatings oriented at $\left[45^{\circ} /-45^{\circ}\right]_{3 s}$ as a function of the distance $x$ along its length.

Figs 5 and 6 show the influence of the core material on the mechanical behavior of thin sandwich beams with composite coatings oriented at $\left[45^{\circ} /-45^{\circ}\right]_{3 s}$ loaded in three-point bending. PVC (H100) foams and Corecell foams give high resistance to sandwich materials with carbon/epoxy and glass/epoxy coatings, while the Alporas and Polyurethane foams give poor behavior to the entire sandwich beam.

The results obtained in Fig 7 confirm the influence of the density on the mechanical behavior of sandwich beams loaded in three-point bending. PVC foam $\mathrm{H} 100$ improves the behavior of sandwich structures with carbon/epoxy or glass/epoxy coatings with fiber orientation of $\left[45^{\circ} /-45^{\circ}\right]_{3 s}$. The PVC foam $\mathrm{H} 45$ gives a low resistance in the cases studied. 


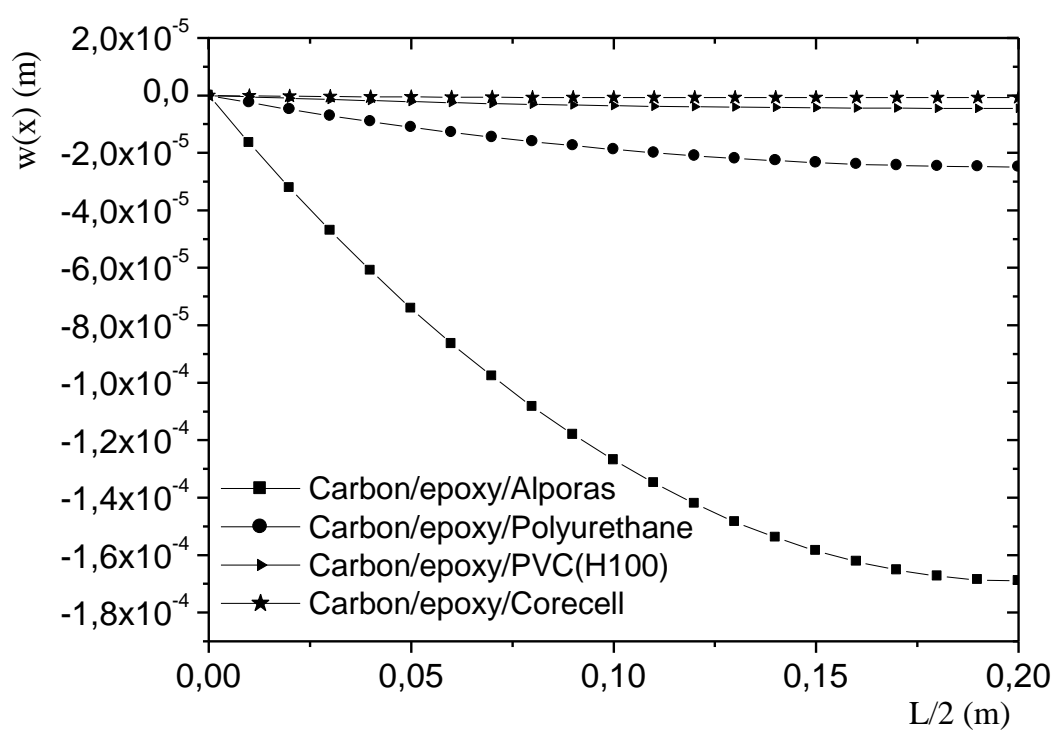

Fig 6. Variation of the deflection of a sandwich beam with different core materials and carbon/epoxy coatings oriented at $\left[45^{\circ} /-45^{\circ}\right]_{3 s}$ as a function of the distance $x$ along its length.

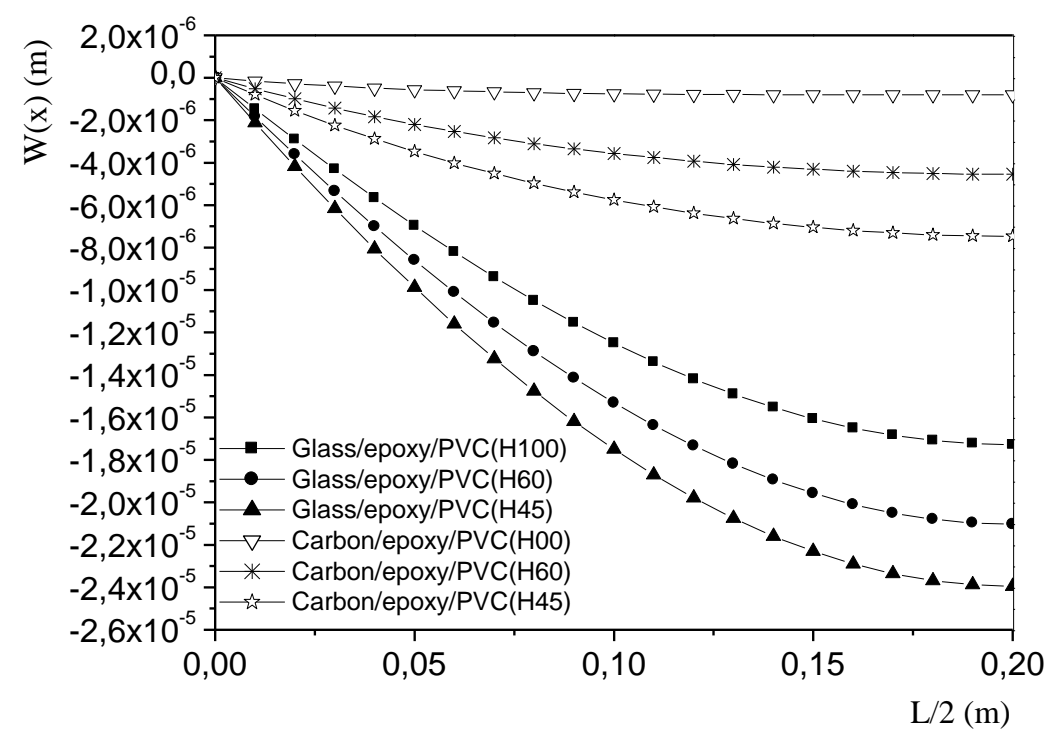

Fig 7. Variation of the deflection of a PVC core sandwich beam with different densities $(\mathrm{H45}, \mathrm{H60}, \mathrm{H100})$ and with glass / epoxy and carbon / epoxy coatings oriented at $\left[45^{\circ} /-45^{\circ}\right]_{3}$ as a function of the distance $x$ along its length.

Fig 8 shows the influence of the thickness of the core on the mechanical behavior of sandwich beams. The three sandwich beams considered have the same PVC foam core material H100 of different thicknesses $6 \mathrm{~mm}, 8 \mathrm{~mm}$, and $10 \mathrm{~mm}$ and with glass/epoxy coatings. The results obtained show that the sandwich material with the thicker core has a good resistance when it is loaded in three-point bending. 


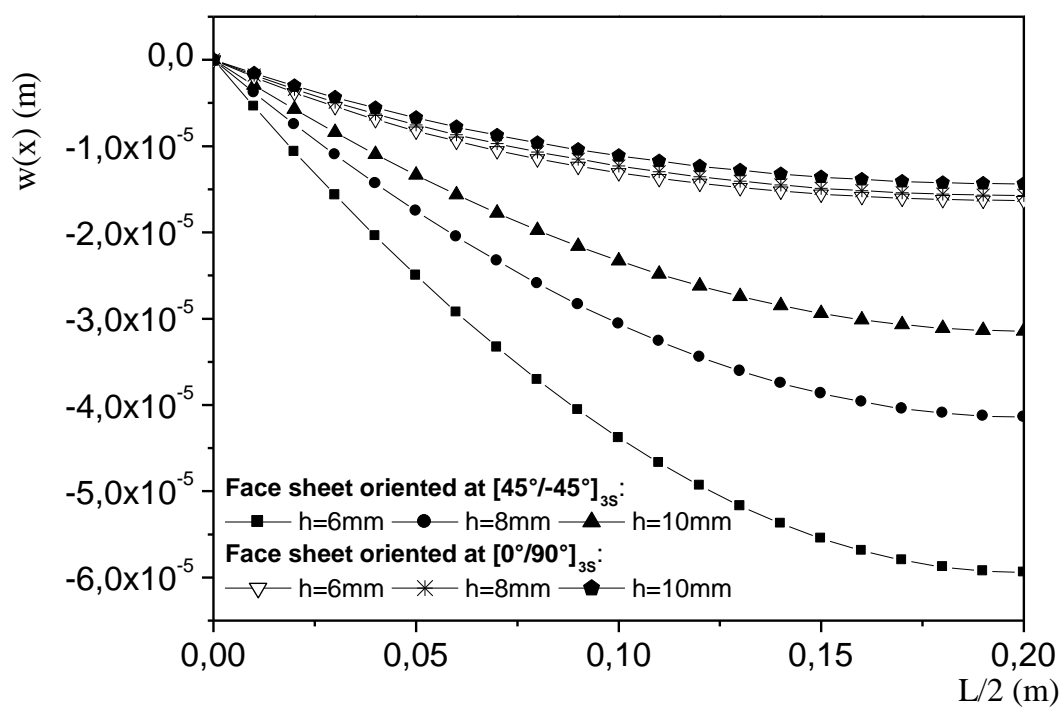

Fig 8. Variation of the deflection of a sandwich beams with glass/epoxy coatings oriented at $\left[0^{\circ} / 90^{\circ}\right] 3 \mathrm{~s}$ and $\left[45^{\circ} /-45^{\circ}\right]_{3 s}$ and PVC foam (H100) core at different thicknesses as a function of the distance $x$ along its length.

\subsection{Optimization of sandwich beams in face yielding and face wrinkling failure modes}

In order to increase the performance of sandwich beams loaded in three-point bending, an optimization program based on the principles of genetic algorithms has been developed to maximize the failure load in face yielding and face wrinkling failure modes, depending on the orientation of the plies.

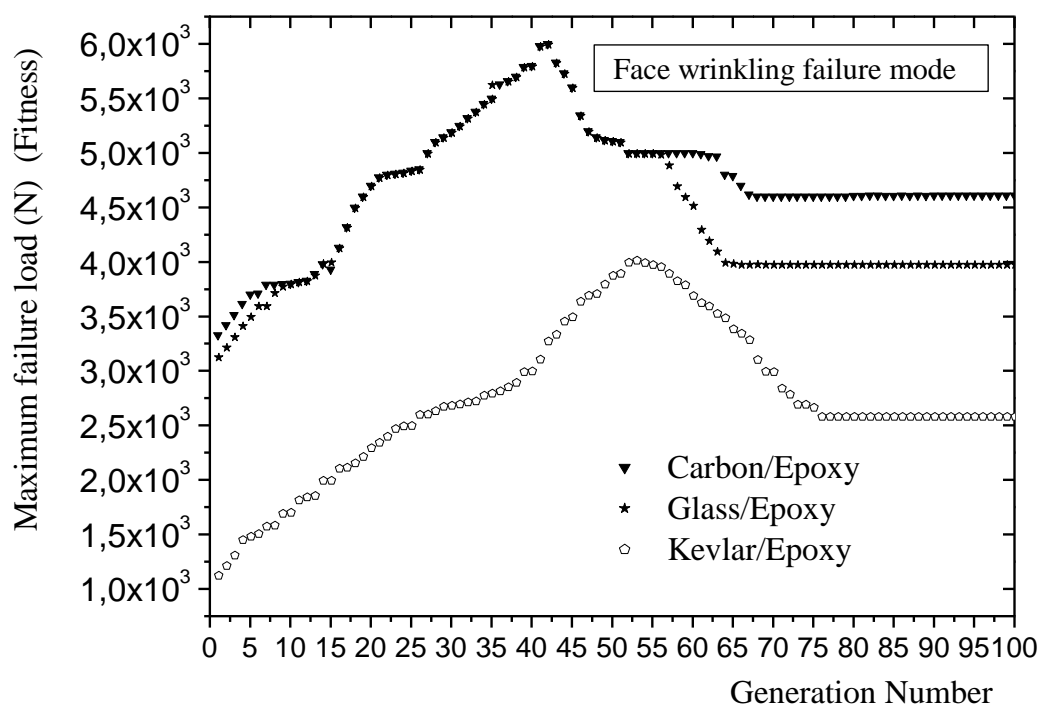

Fig 9. Variation of the failure load of sandwich beams loaded in three-point bending under face wrinkling failure mode with different coating materials for $\mathbf{1 0 0}$ generations.

The beams used are of length $\mathrm{L}=180 \mathrm{~mm}$ and widths $\mathrm{b}=50 \mathrm{~mm}$, and heights $\mathrm{h}=10 \mathrm{~mm}$ and thickness skins $h_{1}=h_{2}=3 \mathrm{~mm}$. The structures considered consist of two skins of composite 
materials with unidirectional fibers of six plies: carbon/epoxy, Kevlar/epoxy, Glass/epoxy. Their mechanical characteristics are summarized in Table 1.

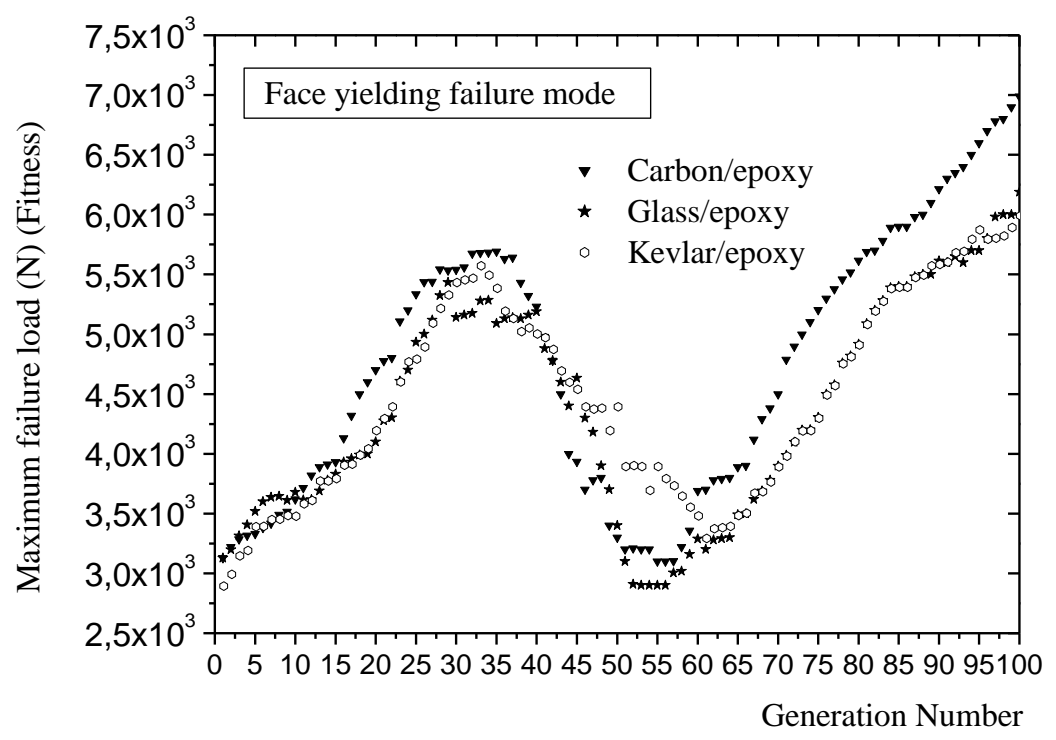

Fig 10. Variation of the failure load of sandwich beams loaded in three-point bending under face yielding failure mode with different coating materials for 100 generations.

Analysis of the results obtained from Fig. 9 shows that for the $10^{\text {th }}$ first generations the beam sandwich with carbon / epoxy coatings appears to have a significantly the higher performance in compression than the other two materials. As of the $11^{\text {th }}$ generation, the cost function deviates similar for sandwich materials with carbon/epoxy and glass/epoxy coatings up to the $55^{\text {th }}$ generation. Beyond that, the failure load of the carbon-epoxy sandwich beams becomes more important. The AG method gives an optimum value for carbon fiber stacks $\left[0^{\circ} / 90^{\circ} /-45^{\circ} /\right.$ $0^{\circ} / 90^{\circ} /+45^{\circ}$ ]. During the evolution of the 100 generations, the sandwich material with Kevlar/epoxy coatings is the least resistant in compression failure mode.

Fig.10 shows that sandwich beams loaded in three point bending with carbon fibers are the best materials in the face yielding failure mode. The Glass fibers promote the first generation to have higher child performance than the two other materials types. Between $10^{\text {th }}$ to $44^{\text {th }}$ generation GA improves the tensile strength of sandwich beams with carbon/epoxy coatings especially from the $63^{\text {th }}$ generation. The optimization program shows also that the sandwich material with Kevlar/epoxy coatings is the better material from the $45^{\text {th }}$ to the $62^{\text {th }}$ generation. The AG converges to the optimum value at the $100^{\text {th }}$ generation with carbon fiber orientated at $\left[0^{\circ} /+45^{\circ} /-45^{\circ} /+45^{\circ} / 90^{\circ} / 90^{\circ}\right]$.

\section{Conclusions}

The objective of this article is to do a comparative study of the mechanical behavior of sandwich beams loaded in three-point bending. The structures are made of two unidirectional skins glass, carbon and Kevlar fibers with epoxy resin which are symmetrical laminates oriented at $\left[0^{\circ} / 90^{\circ}\right]_{3 s}\left[45^{\circ} /-45^{\circ}\right]_{3 s}$, and foam core with, Alporas, Corecel, PVC, or Polyurethane. The different results obtained have shown that the good choice of the material of the coatings and the core improves the mechanical behavior of the sandwich beam loaded in three-point bending. Improving the efficiency and reliability of the design of sandwich structures requires a thorough understanding and accurate modeling of damage to material. In order to optimize the failure load of sandwich structures, stochastic methods presented in the form of a genetic algorithm 
have been used which prove to be good optimization tools because of their capacity to out the local optima. After several combinations, it has been found that the number of generations has a very great influence on the search for the optimal solution. Moreover, it has been observed that some adaptation functions sometimes have particularities that can put the genetic algorithm in difficulty, as in the case of the maximization of the load in face yielding failure mode. This function presents local maxima which make the task particularly difficult to the genetic algorithm. Depending on the number of generations, a local maximum may be confused with the global maximum. The results of optimization in two failure modes face yielding and face wrinkling by the application of a probabilistic method based on the principles of genetic algorithms is acceptable. They confirmed the role of carbon fiber to maximized the failure load in three-point bending of the sandwich beam for stacks $\left[0^{\circ} /+45^{\circ} /-45^{\circ} /+45^{\circ} / 90^{\circ} / 90^{\circ}\right]$ under face yielding failure mode and $\left[0^{\circ} / 90^{\circ} /-45^{\circ} / 0^{\circ} / 90^{\circ} /+45^{\circ}\right]$ under face wrinkling failure mode. It is preferable in face yielding failure mode to change the rate of mutation probability over time to make the environment more stable, or to increase the numbers of the studied generations in order to achieve the best results.

\section{References}

Ashby, M.F., Evans, A.G., Fleck, N.A., Gibson, L.J., Hutchinson, J.W., \& Wadley, H. (2000). Metal foams a design guide, Butter worth Heinemann. United States of America.

Berthelot, J.M. (1996). Mechanical Behaviour of Composite Materials and Structures, Masson., Paris.

Craig, A.S., \& Norman, A.F. (2004). Material selection in sandwich beam constructions. Scripta Materialia, $50,1335-1339$.

Gdoutos, E. E., Daniel, I. M., \& Wang, K. A. (2003). Compression facing wrinkling of composite sandwich structures. Mechanics of materials, 35(3-6), 511-522.

Hamidreza, S., Bahador S., Hoseini ,F.A., \& Ahmadzadeh, M. (2012). Use of Genetic Algorithms for Optimal Design of Sandwich Panels Subjected to Underwater Shock Loading. Strojniski Vestnik/Journal of Mechanical Engineering, 58(3), 156-164.

Jin, D., Thomas, H.H. (2003). Flexural behavior of sandwich beams fabricated by vacuum-assisted resin transfer molding. Composite Structures, 61(3), 247-253.

Tahani, M., Kolahan, F., \& Sarhadi, A. (2005). Genetic algorithm for multi-objective optimal design of sandwich composite laminates with minimum cost and maximum frequency. In International Conference on Advances in Materials, Product Design \& Manufacturing Systems.

Zinker, D. (1995). An Introduction to Sandwich Construction. EMAS Solihull., United Kingdom. 